\title{
A Focal Adhesion Kinase-Derived Peptide Binds the Src SH3 Domain in Two Orientations, As Demonstrated Using Paramagnetic Nuclear Magnetic Resonance
}

\author{
Bharat Somireddy Venkata, $^{\dagger}$ Peter H. J. Keizers, $^{\dagger}$ Jan W. Drijfhout, ${ }^{\ddagger}$ and Marcellus Ubbink ${ }^{*} \dagger$ \\ ${ }^{\dagger}$ Leiden Institute of Chemistry, Leiden University, Einsteinweg 55, 2333 CC Leiden, The Netherlands \\ ${ }^{\ddagger}$ Department of Immunohematology and Blood Transfusion, Leiden University Medical Center (LUMC), P.O. Box 9600, 2300 RC \\ Leiden, The Netherlands
}

\section{Supporting Information}

\begin{abstract}
SH3 binding peptides contain polyproline helices and are classified according to their binding orientations as $\mathrm{N}$-to-C-terminal or C-to- $\mathrm{N}$-terminal. We have tested the hypothesis that such a peptide binds in both orientations but with different populations. A focal adhesion kinase (FAK)-derived peptide was tested for its binding orientation on the Src SH3 domain. Paramagnetic tags were introduced at several positions on the $\mathrm{SH} 3$ domain, and on the basis of the paramagnetic relaxation enhancements (PREs) of the amide protons, the positions of the paramagnetic centers were determined. Two peptides were synthesized with ${ }^{13} \mathrm{C}$-enriched $\mathrm{Ala}$ or Pro, at the $\mathrm{N}$-terminal or $\mathrm{C}$-terminal side of the peptide, and the intermolecular PREs were measured. The results provide compelling evidence that the FAK-derived peptide binds the $\mathrm{SH} 3$ domain in two orientations. In the major state, the $\mathrm{SH} 3$ domain binds the peptide in the $\mathrm{N}-\mathrm{C}$ orientation, whereas $20 \%$ of the time, the peptide binds in the $\mathrm{C}-\mathrm{N}$ orientation. We conclude that the distinction between $\mathrm{N}-$ $\mathrm{C}$ and $\mathrm{C}-\mathrm{N}$ orientations, which is based on crystal structures, might be artificial. The pseudosymmetric nature of the polyproline helix might allow for binding in both orientations in the solution state.
\end{abstract}

rc belongs to the non-receptor tyrosine kinase family. The $\checkmark$ Src family of kinases is involved in many cellular processes, including cell motility, apoptosis, cell adhesion, cell cycle control, cell differentiation, and signal transduction. ${ }^{1-7} \mathrm{Src}$ is a modular protein in which several domains have a function in the recognition of binding partners. It is $60 \mathrm{kDa}$ in mass and contains an $\mathrm{N}$-terminal SH4 domain, an $\mathrm{SH} 3$ domain, an $\mathrm{SH} 2$ domain, a kinase domain, and a $\mathrm{C}$-terminal regulatory region. The three-dimensional structure of the $\mathrm{Src} \mathrm{SH} 3$ domain comprises a sheet of antiparallel $\beta$-strands. It also contains a short helix near the C-terminal end and three loops, namely, the RT loop (so-called because it generally contains arginine and threonine residues), the $\mathrm{nSrc}$ loop (neuronal isoform), and the distal loop.

The Src $\mathrm{SH} 3$ domains are diverse in their ligand recognition. ${ }^{8,9}$ In most cases, they bind to ligands that have a "PxxP" motif, although they can also bind atypical ligands. ${ }^{10-15}$ In the PxxP motif, $\mathrm{P}$ stands for proline, $\mathrm{x}$ preceding the second proline is generally an aliphatic residue, and the other $\mathrm{x}$ stands for any amino acid residue. ${ }^{16}$ The ligand binding site on $\mathrm{SH} 3$ domains is located between the RT loop and n-Src loop. This binding site consists of two hydrophobic pockets formed by highly conserved aromatic residues and interacting with the two proline residues. The third pocket on the $\mathrm{SH} 3$ domain is called the specificity pocket and consists of a negatively charged residue that forms a salt bridge with an oppositely charged residue, either Arg or Lys, ${ }^{17,18}$ flanking the core "PxxP" motif of the ligand. The ligands that contain the PxxP motif typically adopt a polyproline II (PPII) helical conformation. Because of its pseudosymmetry, such peptides can bind in two orientations on the SH3 domain. Crystal structures have shown that peptides that bind to the $\mathrm{SH} 3$ domains of c-Src SH3, PI3K, Abl, and Fyn tyrosine kinases adopt an $\mathrm{N}$-terminal-to-C-terminal orientation $(\mathrm{N}-\mathrm{C}),{ }^{18-21}$ and these are known as class 1 peptides. In other cases, peptides are in an opposite orientation $(\mathrm{C}-\mathrm{N}),{ }^{18,22-24}$ and these are classified as class 2 peptides. The binding orientation of the peptide depends on the relative positioning of the Arg or Lys residue that is present either $\mathrm{N}$ - or C-terminal of the "PxxP" sequence ( $+\mathrm{xxPxxP}$ or $\mathrm{xPxxP}+)$, yielding the $\mathrm{N}-\mathrm{C}$ or $\mathrm{C}-\mathrm{N}$ orientation, respectively. In the case of the c-Src SH3 domain, peptides with different relative positions of arginine bind in these different orientations. The arginine of the peptide makes a salt bridge with an aspartate residue (D101 in our study). ${ }^{17}$ Mutation of this aspartate residue reduced not only the binding affinity but also the specificity toward the recognition of peptides. $^{25}$

Previous work in our group ${ }^{26,27}$ showed that a focal adhesion kinase (FAK)-derived peptide was able to bind to the $\mathrm{Src} \mathrm{SH} 3$ domain. In that work, three peptides were synthesized

Received: September 9, 2015

Revised: December 8, 2015

Published: December 8, 2015 
separately with a paramagnetic TOAC spin-label placed at different positions, at the $\mathrm{C}$-terminus, at the $\mathrm{N}$-terminus, and in the PXXP sequence. The interactions between these peptides and the ${ }^{15} \mathrm{~N}$-labeled Src SH3 domain were studied to determine the dynamics of the protein-peptide interaction. ${ }^{26}$ Although the complex between the $\mathrm{Src} \mathrm{SH} 3$ domain and FAK peptide was weak and transient, it was observed that the peptide binds in a well-defined position on the protein and not in a dynamic encounter state. However, the data also showed that a peptide containing a TOAC spin-label at the C-terminus showed paramagnetic effects on residue Asp 93 of the $\mathrm{Src} \mathrm{SH} 3$ domain, even though this residue was at a considerable distance from the spin-label. This observation could be explained if two orientations of peptide binding are possible, with the major orientation being $\mathrm{N}-\mathrm{C}$ and a small fraction in the alternative $\mathrm{C}-\mathrm{N}$ orientation. That would suggest that the distinction in two classes of SH3 domains based on peptide orientation does not reflect the true situation in solution and is merely a consequence of the static nature of crystal structures. To test this hypothesis and determine the orientation(s) of binding of a class 1 peptide to the $\mathrm{Src} \mathrm{SH} 3$ domain, we applied paramagnetic NMR spectroscopy using several tags. The combination of paramagnetism with NMR represents a powerful tool for detecting the presence of minor states in protein-peptide, protein-protein, and protein-DNA complexes. ${ }^{28-31}$ The concept of the experiment is shown in Figure 1. A paramagnetic label will affect only part of the peptide if bound in a single orientation. If it binds in the opposite orientation during a fraction of the time, the other end of the peptide should also experience paramagnetic effects.

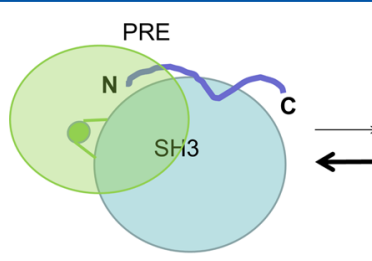

Class-1 orientation

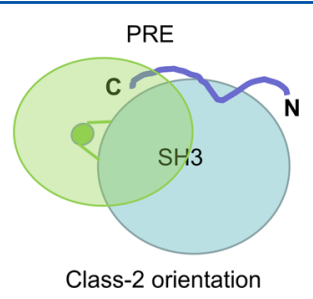

Class-2 orientation
Figure 1. Experimental approach. The $\mathrm{SH} 3$ domain is tagged with a paramagnetic center, and the peptide is isotope-labeled and observed in NMR experiments. If the peptide spends a small fraction of the time in the $\mathrm{C}-\mathrm{N}$ orientation, paramagnetic relaxation enhancement should be observed for nuclei at both ends of the peptide.

\section{EXPERIMENTAL PROCEDURES}

Site-Directed Mutagenesis. Cysteine residues were introduced into the $\mathrm{SH} 3$ domain by mutagenesis of plasmid pET28aSH3 ${ }^{26}$ using the whole-plasmid synthesis method (QuikChange, Stratagene, La Jolla, CA) with the oligonucleotides listed in Table 1 and their complements.

Table 1. Primers Used To Create Mutations on the SH3 Domain $^{a}$

$\begin{array}{ll}\text { T116C/ } & \text { GCAGATTGTTAACAACTGCTGCGGGGACTGGTGGC } \\ \text { E117C } & \\ \text { T98C } & \text { TATGAGTCACGGTGTGAGACTGACCTG } \\ \text { T100C } & \text { TCACGGACAGAGTGTGACCTGTCCTTC } \\ \text { L91C } & \text { ACCTTTGTGGCCTGTTATGACTATGAG }\end{array}$

${ }^{a_{\text {The }}}$ codons for cysteine are shown in bold.
Protein Production. Escherichia coli BL21 cells were transformed with wt or mutant pET28aSH3. LB medium (3 $\mathrm{mL})$ was inoculated with fresh transformants. After overnight incubation, the preculture was used to inoculate a $1 \mathrm{~L}$ culture $(2$ $\times 500 \mathrm{~mL}$ in $2 \mathrm{~L}$ Erlenmeyer flasks). The ${ }^{14} \mathrm{~N}$-labeled SH3 domain was produced in $\mathrm{LB}$ medium, whereas the ${ }^{15} \mathrm{~N}$-enriched protein was produced in $\mathrm{M} 9$ minimal medium with ${ }^{15} \mathrm{NH}_{4} \mathrm{Cl}$ as the sole nitrogen source. The cultures were incubated at $37^{\circ} \mathrm{C}$ and shaken at $200 \mathrm{rpm}$. Gene expression was induced by addition of isopropyl $\beta$-D-1-thiogalactopyranoside $(0.5 \mathrm{mM})$ when the culture was at an $\mathrm{OD}_{600}$ of 0.6. The cultures were harvested $4 \mathrm{~h}$ after induction by centrifugation at $3439 \mathrm{~g}$, and the pellets were resuspended in lysis buffer containing $20 \mathrm{mM}$ Tris-HCl ( $\mathrm{pH} 8), 0.5 \mathrm{M} \mathrm{NaCl}, 10 \mathrm{mM}$ imidazole, and $1 \mathrm{mM}$ phenylmethanesulfonyl fluoride. The resuspended pellets were flash-frozen using liquid $\mathrm{N}_{2}$ and stored at $-80{ }^{\circ} \mathrm{C}$.

Protein Purification. Immediately before lysis of the cells, $25 \mu \mathrm{g} / \mathrm{mL}$ DNase was added to the resuspended culture. The cells were lysed when the suspension was passed through a French press twice at a pressure of 1000 psi. The lysate was cleared by ultracentrifugation at $40000 \mathrm{rpm}(192700 \mathrm{~g})$ for 40 $\mathrm{min}$. The supernatant was further cleared by passing the sample through a filter $(0.4 \mu \mathrm{m})$ and loaded on a nickel affinity column (HisTrap HP, GE Healthcare), which had been preequilibrated with a loading buffer containing $20 \mathrm{mM}$ Tris$\mathrm{HCl}(\mathrm{pH} 8), 0.5 \mathrm{M} \mathrm{NaCl}$, and $10 \mathrm{mM}$ imidazole. The protein was eluted by applying an imidazole gradient from 10 to 500 $\mathrm{mM}$. The eluted protein was pooled, concentrated to $5 \mathrm{~mL}$, and loaded on a Superose $12(10 \mathrm{~mm} \times 300 \mathrm{~mm})$ gel filtration column, pre-equilibrated with a buffer containing $20 \mathrm{mM} \mathrm{KP}$ (pH 6.5) and $100 \mathrm{mM} \mathrm{NaCl}$ (NMR buffer). The purity was shown to be $>95 \%$ by $15 \%$ sodium dodecyl sulfatepolyacrylamide gel electrophoresis. The concentration of the protein was measured at $280 \mathrm{~nm}$, using the theoretical extinction coefficient of $16960 \mathrm{M}^{-1} \mathrm{~cm}^{-1}$.

Peptide Synthesis. Peptides with the sequence RALPSIPKLA were prepared by Fmoc chemistry using preloaded Tentagel resins, benzotriazol-1-yl-oxy-tris-pyrrolidino-phosphonium hexafluorophosphate/ $N$-methylmorpholine (PyBop/ NMM) for in situ activation, and $20 \%$ piperidine in $N$ methyl-2-pyrrolidone (NMP) for Fmoc removal. ${ }^{32}$ Couplings were performed for $75 \mathrm{~min}$. After final Fmoc removal, peptides were cleaved with a 19/1 trifluoroacetic acid (TFA) $/ \mathrm{H}_{2} \mathrm{O}$ mixture and isolated by diethyl ether/pentane precipitation. The peptides were stored at $-20{ }^{\circ} \mathrm{C}$ until they were used. The purity of the peptides was checked using reversed-phase highperformance liquid chromatography and their integrity using mass spectrometry. Peptide stock solutions were prepared by weighing out the peptide, dissolving it in NMR buffer, and adjusting the $\mathrm{pH}$ by the addition of small aliquots of $\mathrm{NaOH}$ or $\mathrm{HCl}$. Isotope-labeled Fmoc amino acids were purchased from Sigma-Aldrich Chemie B.V. (Zwijndrecht, The Netherlands).

Paramagnetic Probe Attachment. A double-cysteine SH3 mutant was used for attachment of a Caged Lanthanoid NMR Probe (CLaNP-5), ${ }^{33,34}$ whereas MTSL [(1-oxyl-2,2,5,5tetramethylpyrrolidin-3-yl)methyl)-methanethiosulfonate] was linked to the single-cysteine mutants. First, the SH3 mutant protein was incubated with $5 \mathrm{mM}$ DTT for $60 \mathrm{~min}$ at room temperature. The DTT was removed by passing the protein over a PD10 column (GE Healthcare). Ten molar equivalents of CLaNP-5 or spin-label were added immediately to the eluted protein, and the solution was incubated for $2 \mathrm{~h}$ at room temperature. The protein was then loaded on a Superdex G75 
gel filtration column to remove dimers and oligomers, as well as excess probe or spin-label. The protein was eluted using NMR buffer $\left[20 \mathrm{mM} \mathrm{KP}_{\mathrm{i}}(\mathrm{pH} 6.5)\right.$ and $\left.100 \mathrm{mM} \mathrm{NaCl}\right]$. Probe attachment was confirmed by mass spectrometry, and the percentage of the paramagnetic spin-label (MTSL) was determined by electron paramagnetic resonance (EPR). The double integral of EPR signals measured for all mutants of SH3MTSL versus a standard sample of free MTSL indicated that $>95 \%$ of the protein was labeled with MTSL. The protein was concentrated and used for further NMR measurements. For the double-cysteine mutant, CLaNP-5-Gd was used to observe paramagnetic effects and CLaNP-5-Lu served as the diamagnetic control. For the single-cysteine mutants, MTS [(1-acetyl2,2,5,5-tetramethyl-3-pyrroline-3-methyl)-methanethiosulfonate] was used as the diamagnetic control.

NMR Experiments. For all NMR experiments, the protein concentration was 50-200 $\mu \mathrm{M}$, the concentrations of the peptide stocks were $5 \mathrm{mM}$, and the peptides were dissolved in NMR buffer. The $\mathrm{pH}$ was adjusted to 6.5 with small aliquots of $0.1-0.5 \mathrm{M}$ solutions of $\mathrm{NaOH}$ or $\mathrm{HCl}$. Intramolecular PREs in the $\mathrm{SH} 3$ domain were determined by recording $\left[{ }^{1} \mathrm{H},{ }^{15} \mathrm{~N}\right]$ HSQC spectra. Intermolecular PREs between the Src SH3 domain and the peptide were obtained from $\left[{ }^{1} \mathrm{H},{ }^{13} \mathrm{C}\right]$ constant time HSQC (CT-HSQC) NMR experiments to achieve the high spectral resolution and ensure reliable calculations of PREs. Relaxation delays of $1.5 \mathrm{~s}$ were used. The constant time period was set to $26 \mathrm{~ms}$. NMR experiments were recorded on a Bruker DMX or Avance III $600 \mathrm{MHz}$ NMR spectrometer, equipped with a TCI-Z-GRAD cryoprobe at $298 \mathrm{~K}$. NMR data were processed using nmrPipe ${ }^{35}$ and analyzed using CCPN Analysis 2.1.5. ${ }^{36}$ The $\mathrm{Src} \mathrm{SH} 3$ domain resonances were assigned with the help of assignments reported for the chicken Src SH3-SH2 domains. ${ }^{37}$ The transverse relaxation rate of resonances in the diamagnetic sample $\left(R_{\text {dia }}^{\mathrm{H}}\right)$ was determined after processing with a $2 \mathrm{~Hz}$ line-broadening exponential window function. The line width at half-maximum, $\Delta v_{1 / 2}$, was calculated from a Lorentzian line shape fit using the software FuDA (http://pound.med.utoronto.ca/software.html).

After correction for the artificial line-broadening, the $\mathrm{R}_{\text {dia }}^{H}$ was obtained from eq 1 .

$$
\begin{aligned}
& R_{2, \text { dia }}^{\mathrm{H}}=\pi \Delta v_{1 / 2} \\
& \frac{I_{\text {para }}}{I_{\text {dia }}}=\frac{R_{2, \text { dia }}^{\mathrm{H}} \mathrm{e}^{-R_{2, \text { para }}^{\mathrm{H}} \tau}}{R_{2, \text { dia }}^{\mathrm{H}}+R_{2, \text { para }}^{\mathrm{H}}}
\end{aligned}
$$

The rate of transverse relaxation of protons due to the paramagnetic enhancement effect $\left(R_{2, \text { para }}^{\mathrm{H}}\right)$ was calculated using eq $2^{38}$ for protein amide protons and eq 3 for peptide carbonbound protons. Equation 3 is an extension of eq 2 . In ${ }^{1} \mathrm{H}-{ }^{15} \mathrm{~N}$ spectra, the paramagnetic transverse relaxation of ${ }^{15} \mathrm{~N}$ is neglected, because ${ }^{15} \mathrm{~N}$ is 100 -fold less sensitive for PRE than ${ }^{1} \mathrm{H}$. For ${ }^{13} \mathrm{C}$ nuclei, this factor is only 16 , and furthermore, in the $\mathrm{CT}$ experiments, the ${ }^{13} \mathrm{C}$ spends a relatively long time in the transverse plane; thus, the ${ }^{13} \mathrm{C}$ relaxation contributes significantly to the intensity reduction of the HSQC peak.

$$
\frac{I_{\text {para }}}{I_{\text {dia }}}=\frac{R_{2, \text { dia }}^{\mathrm{H}} \mathrm{e}^{-\left(R_{2, \text { para }}^{\mathrm{H}} \Delta^{\mathrm{H}}+R_{2, \text { para }}^{\mathrm{C}} \Delta^{\mathrm{C}}\right)}}{R_{2, \text { dia }}^{\mathrm{H}}+R_{2, \text { para }}^{\mathrm{H}}}
$$

where $I_{\text {para }}$ and $I_{\text {dia }}$ are the paramagnetic and diamagnetic peak intensities, respectively, and $\Delta^{\mathrm{H}}$ and $\Delta^{\mathrm{C}}$ are the times that the ${ }^{1} \mathrm{H}$ and ${ }^{13} \mathrm{C}$ magnetization coherences, respectively, are in the transverse plane during the CT-HSQC experiment (14.4 and $26 \mathrm{~ms}$, respectively). $R_{2, \text { para }}^{\mathrm{C}}$ was taken to be equal to $R_{2, \text { para }}^{\mathrm{H}} / 16$. Distances were derived from $R_{2, \text { para }}^{\mathrm{H}}$ using eq 4:

$$
r=\sqrt[6]{\frac{\gamma_{\mathrm{H}}^{2} g^{2} \beta^{2} \mu_{0}{ }^{2} S(S+1)}{240 \pi^{2} R_{2, \text { para }}^{\mathrm{H}}}\left(4 \tau_{\mathrm{c}}+\frac{3 \tau_{\mathrm{c}}}{1+\tau_{\mathrm{c}}{ }^{2}{\omega_{\mathrm{H}}}^{2}}\right)}
$$

where $\gamma_{\mathrm{H}}$ is the gyromagnetic ratio of ${ }^{1} \mathrm{H}, g$ is the electronic $\mathrm{g}$ factor, $\beta$ is the Bohr magneton, $\mu_{0}$ is the permeability of a vacuum, $S$ is the spin quantum number of the paramagnet, and $\omega_{\mathrm{H}}$ is the proton Larmor frequency. The rotational correlation time $\tau_{\mathrm{c}}$ of the protein-peptide complex was estimated to be 5 ns, using the software hydroNMR ${ }^{39}$ and a structure of chicken Src SH3 bound to a similar peptide [RALPPLPRY, Protein Data Bank (PDB) entry 1RLQ]. ${ }^{17}$ The $R_{2, \text { para }}^{\mathrm{H}}$ values obtained with eq 3 for peptide nuclei are a population-weighted average of PREs in the free peptide (no PRE) and the bound form, so they were first extrapolated to the $100 \%$ bound form of the peptide. For example, the concentrations of peptide and CLaNP-tagged SH3 T116C/E117C were 160 and $80 \mu \mathrm{M}$, respectively. With a $K_{\mathrm{d}}$ of $316 \mu \mathrm{M}$, it can be calculated that the fraction of bound peptide is $15 \%$, so the observed PREs were divided by 0.15 .

Positioning the Paramagnetic Centers. PDB entry 1RLQ was modified by mutating the peptide to the FAK sequence RALPSIPKLA, which constitutes residues 368-377 in Uniprot entry Q05397 for human FAK. Here, the peptide amino acids are numbered from 1 to 10 . The sequences of mouse Src SH3 and chicken Src SH3 are the same except for residue Thr 127 in the mouse form, which is Ser in the chicken form. In structure $1 R L Q$, this residue was changed to $T h r$ in the docking calculations. To determine the positions of the paramagnetic centers, a pseudoatom was docked on the $\mathrm{SH} 3$ protein on the basis of the distances derived from protein PREs by using Xplor-NIH. ${ }^{40}$ An example of a script used for docking is included in the Supporting Information. On the basis of the ratios of $I_{\text {para }}$ and $I_{\mathrm{dia}}$ the nuclei were divided into three classes. In class 1 were those for which the resonance disappeared in the paramagnetic spectrum. The ratio for these nuclei was defined by using the noise level of the paramagnetic spectrum as the value of $I_{\text {para. }}$ The nuclei in class 2 had ratios of $I_{\text {para }}$ and $I_{\text {dia }}$ between 0 and 0.9 and the nuclei in class 3 were those that had ratios of $I_{\text {para }}$ and $I_{\text {dia }}$ of $>0.9$. For these, $I_{\text {para }}$ was set to 0.9 to obtain a minimum distance. Class 1 nuclei yielded distance restraints to the paramagnetic center with only an upper bound, class 2 with upper and lower bounds (the calculated distance with an estimated error of $\pm 3 \AA$ ), and class 3 with only a lower bound. For T98C and T100C, two positions were calculated, representing the two forms observed for the MTSL-bound SH3 domain (see below). The PRE-derived distances from the MTSL oxygen atom at these two positions to nuclei in the peptides were averaged $\left(r^{-6}\right)$, because the peptides sample multiple $\mathrm{SH} 3$ molecules rapidly (fast exchange regime).

Fit Quality. The agreement between observed and backcalculated NMR observables $(O)$ was expressed in a quality factor, $Q$ given in eq $5 .{ }^{41}$ Note that the observed and calculated observables are added in the denominator. Only class 2 restraints were used to calculate $Q$.

$$
Q=\sqrt{\frac{\sum_{i}\left[O^{\text {calc }}(i)-O^{\text {obs }}(i)\right]^{2}}{\sum_{i}\left[O^{\text {calc }}(i)+O^{\text {obs }}(i)\right]^{2}}}
$$




\section{RESULTS AND DISCUSSION}

To study the interaction of the mouse $\mathrm{Src} \mathrm{SH} 3$ domain with the SH3 binding motif RALPSIPKLA of FAK, paramagnetic centers were attached to the $\mathrm{SH} 3$ domain. The sites of introduction of single cysteine residues and a cysteine pair, for attachment of MTSL spin-labels and the lanthanoid probe CLaNP-5, ${ }^{33,34}$ respectively, are shown in Figure 2.

A

Mouse Src SH3 Uniprot Q80XU2

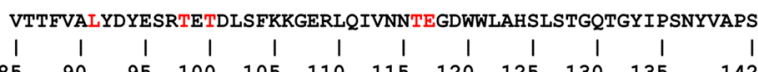

B

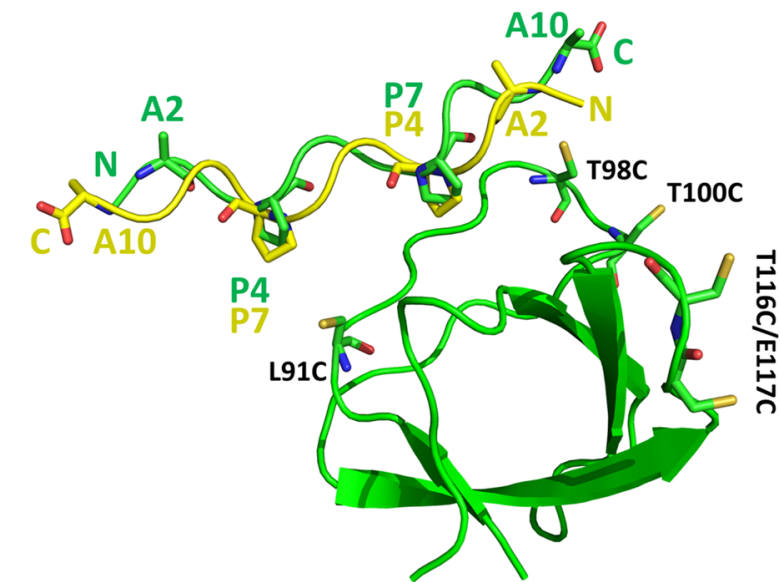

Figure 2. Probe attachment sites. (A) Amino acid sequence of the mouse Src SH3 domain. The residues colored red were mutated individually to Cys, except for the T116C/E117C mutant, which was a double Cys mutation. The numbering is based on Uniprot entry Q80XU2 and used throughout. The numbering in PDB entry $1 \mathrm{RLQ}^{17}$ differs by -78 . (B) Three-dimensional representation of the $\mathrm{SH} 3$ domain (green ribbon) bound to a class 1 peptide (green coil, PDB entry 1RLQ). The cysteine substitutions for the attachment of paramagnetic probes have been modeled and are shown in stick representation, with black labels. The peptide modeled in the $\mathrm{C}-\mathrm{N}$ orientation is colored yellow. The peptide residues that were labeled with ${ }^{13} \mathrm{C}$ are shown as sticks and labeled in the color of the peptide. The $\mathrm{N}$ - and $\mathrm{C}$-termini of the peptides are indicated.

Effects of Probe Attachment on the SH3-Peptide Interaction. To verify the influence of paramagnetic probes attached to the SH3 domain on binding of the FAK peptide, the dissociation constants $\left(K_{\mathrm{d}}\right)$ for each mutant were determined by $\mathrm{SH} 3$ amide chemical shift titrations for the complexes of the peptide and the $\mathrm{SH} 3$ domain linked to diamagnetic control probes, Lu-CLaNP-5 or MTS (Figure S1 of the Supporting Information). With the obtained $K_{\mathrm{d}}$ values, the CSP values were extrapolated to $100 \%$ bound $\mathrm{SH} 3$ and the averaged amide CSP values were mapped on the $\mathrm{SH} 3$ structure for comparison to the wt $\mathrm{SH} 3$ binding map (Figure 3 and Figure S2). The $K_{\mathrm{d}}$ value of mutant L91C $(53 \pm 1 \mu \mathrm{M})$ for peptide binding is very similar to that of wt SH3 $(63 \pm 3 \mu \mathrm{M})$. For mutants $\mathrm{T} 100 \mathrm{C}$ and $\mathrm{T} 116 \mathrm{C} / \mathrm{E} 117 \mathrm{C}$, the $K_{\mathrm{d}}$ values were 3and 5-fold larger, respectively. For T98C, MTS(L) attachment resulted in doubling of 15 peaks. The pairs of peaks had about the same intensity, suggesting that spin-label binding results in two conformations that are in slow exchange and equally populated. Both forms were able to bind the peptide, with $K_{\mathrm{d}}$ values of $191 \pm 11 \mu \mathrm{M}$ (conformer A) and $393 \pm 18 \mu \mathrm{M}$ (conformer B), and show very similar chemical shift perturbation patterns. As the two forms could be distinguished

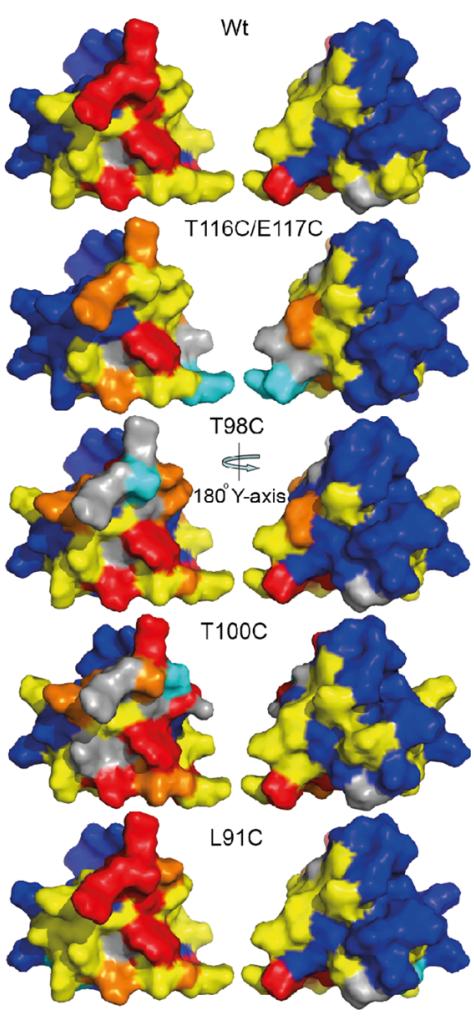

Figure 3. Amide chemical shift perturbations $\left[\Delta \delta_{\mathrm{Avg}}=\left(1 /{ }_{2} \Delta \delta_{\mathrm{H}}{ }^{2}+\right.\right.$ $\left.\left.\Delta \delta_{\mathrm{N}}^{2} / 50\right)^{1 / 2}\right]$ of the SH3 domain upon binding of FAK peptide. The shift changes are extrapolated to $100 \%$ bound $\mathrm{SH} 3$. The colors represent the size of $\Delta \delta_{\text {Avg }}$ : red for $\Delta \delta_{\text {Avg }} \geq 0.25 \mathrm{ppm}$, orange for 0.25 ppm $>\Delta \delta_{\text {Avg }} \geq 0.15$ ppm, yellow for $0.15 \mathrm{ppm}>\Delta \delta_{\text {Avg }} \geq 0.05 \mathrm{ppm}$, and blue for $\Delta \delta_{\text {Avg }}<0.05 \mathrm{ppm}$. Unassigned residues and residues broadened upon peptide binding are colored gray. Probe attachment sites are colored cyan.

on the basis of their difference in affinity for the peptide, they were treated separately in further experiments. Also for T100C, a few peaks were doubled, suggesting that the spin-label at this position assumes two orientations. A titration experiment indicated that the affinity for the peptide was almost the same for both conformers. The binding maps for all variants bound to MTS closely resemble the map of wt SH3 (Figure 3). The extrapolated CSP values for $\mathrm{SH} 3$ attached to CLaNP are smaller than for wt, but the binding pattern is similar. Thus, we conclude that probe attachment has some effects on the strength of the binding interaction, but the specificity of binding remains unaffected, based on the CSP values.

Localization of the Paramagnetic Centers on the $\mathrm{SH} 3$ Domain. The positions of the paramagnetic centers relative to the protein were determined. For this purpose, the protein was enriched with ${ }^{15} \mathrm{~N}$ and the peptide was added in 5-fold access to push the binding equilibrium to the bound state of the protein. $\left[{ }^{1} \mathrm{H},{ }^{15} \mathrm{~N}\right] \mathrm{HSQC}$ spectra were recorded for each $\mathrm{SH} 3$ variant of the diamagnetic control samples (Lu-CLaNP-5-SH3-peptide and MTS-SH3-peptide complexes) as well as the paramagnetic samples (Gd-CLaNP-5-SH3-peptide and MTSL-SH3-peptide complexes). The ratios between the intensity of the paramagnetic peak, $I_{\text {para }}$ and that of the diamagnetic peak, $I_{\text {dia }}$ of the amide resonances (Figure S3) were used to calculate the distances between each amide proton and the corresponding paramagnetic center. With these distances, the position of the paramagnetic center relative to the protein was determined (Figure S4; see Experimental Procedures for details). The 


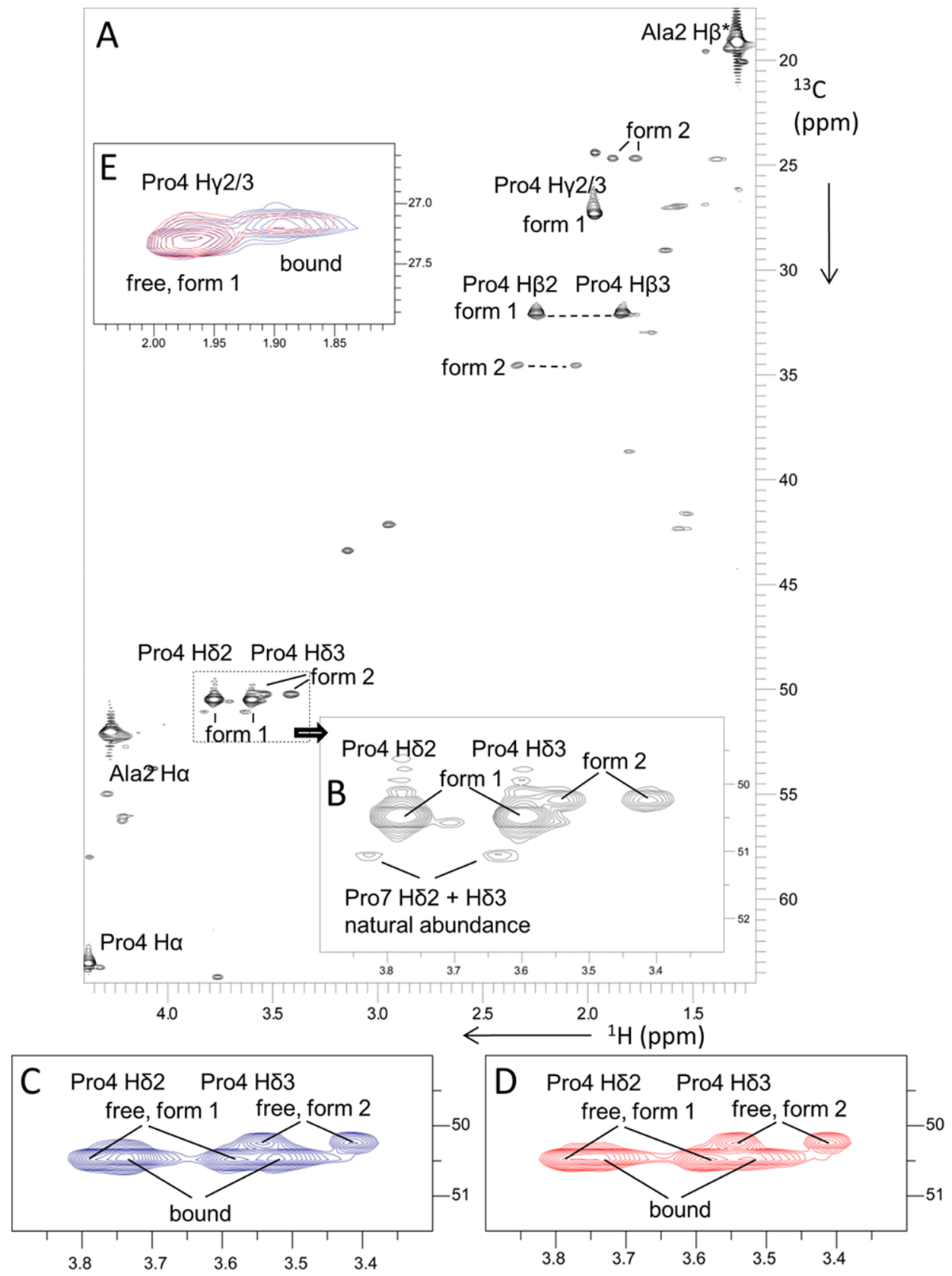

Figure 4. $\left[{ }^{13} \mathrm{C},{ }^{1} \mathrm{H}\right]$ CT-HSQC spectrum of the FAK peptide (RALPSIPKLA, ${ }^{13} \mathrm{C}$-labeled residues underlined). (A) Spectrum of the free peptide with assignments for Ala2 and Pro4. Form 1 comprises the transPro4-transPro7 and transPro4-cisPro7 forms. Form 2 represents the cisPro4transPro7 form of the peptide. Assignments are listed in Table S2. (B) Detail of panel A showing the Pro4 $\mathrm{H} \delta$ protons as well as form 1 of the Pro7 $\mathrm{H} \delta$ protons at natural abundance. (C and D) The same spectral region as in panel B is shown of the peptide in the presence of SH3 domain T98CMTS (C) and T98C-MTSL (D). (E) Detail of the same samples as in panels C and D, showing the overlay of spectra with SH3 domain T98C-MTS (blue) and T98C-MTSL (red) for the $\mathrm{H} \gamma 2 / 3$ peak. The peptide and $\mathrm{SH} 3$ domain concentrations were 1 and $0.2 \mathrm{mM}$, respectively.

distances from the metal or oxygen atom to the $\mathrm{C} \alpha$ atoms of the cysteines are listed in Table S1. For the spin-labels on T98C and T100C, two positions were calculated, representing the two forms in slow exchange.

PREs of the ${ }^{13} \mathrm{C}$-Labeled Peptide in Complex with the SH3 Domain. Two versions of the FAK peptide were synthesized, with ${ }^{13} \mathrm{C}$-labeled $\mathrm{Ala}$ and Pro residues close to the N-terminus, RALPSIPKLA (peptide 1, labeled residues underlined), and the C-terminus, RALPSIPKLA (peptide 2). ${ }^{13} \mathrm{C}$ HSQC spectra were recorded for the free peptide and in the presence of the $\mathrm{SH} 3$ domain with a 5-fold molar excess of the peptide (Figure 4 and Figure S5). Nine resonances are expected in the ${ }^{1} \mathrm{H}$ dimension, two from $\mathrm{Ala}(\mathrm{H} \alpha$ and $\mathrm{H} \beta)$ and seven from Pro ( $\mathrm{H} \alpha, \mathrm{H} \beta 2$ and $-3, \mathrm{H} \gamma 2$ and -3 , and $\mathrm{H} \delta 2$ and -3 ), as well as some weak natural abundance signals. However, it turned out that the peptide occurs in three forms. In the free form, a major form and a minor form are detected. When $\mathrm{SH} 3$ binds, the minor form is not affected. The major form splits into two peaks, one that shifts proportionally with the fraction peptide bound and another that remains at the position of free peptide. We interpret this observation as follows. Three forms are present, and these forms exchange slowly on the NMR time scale. Only one of these is capable of binding to the $\mathrm{SH} 3$ domain, and this process is in the fast exchange regime. The 
${ }^{13} \mathrm{C}$ chemical shifts of the three forms (Table S2) indicate that both proline residues can assume a cis conformation, which can be deduced from the characteristic chemical shift differences of the $\beta$ and $\gamma$ nuclei. The relative peak intensities indicate a population of $\sim 8 \%$ for each cis Pro-containing peptide. In the major form (84\%), both prolines are in the trans conformation. The double cis conformation is expected to have a population that is too small to be observed. The double trans form is the one that binds to the $\mathrm{SH} 3$ domain. For peptide 1, in which Pro4 is labeled, transPro4-transPro7 and transPro4-cisPro7 have the same chemical shifts, but only transPro4-transPro7 binds to the $\mathrm{SH} 3$ domain, causing a splitting of the major peak (form 1). The analogous situation is observed for peptide 2 .

The peak intensities in the spectra of the peptide in the presence of either MTS- or MTSL-labeled SH3 domain were compared to obtain the $I_{\text {para }} / I_{\text {dia }}$ ratio (Figure 5). As a consequence of the partial overlap between the peaks of the different forms, the PREs of only a subset of signals could be determined. The peptide was in excess of the protein and is only partly bound. Consequently, the PREs are a weighted average of the free (no PRE) and bound states. Thus, the PREs calculated from the $I_{\text {para }} / I_{\text {dia }}$ ratios were extrapolated to the

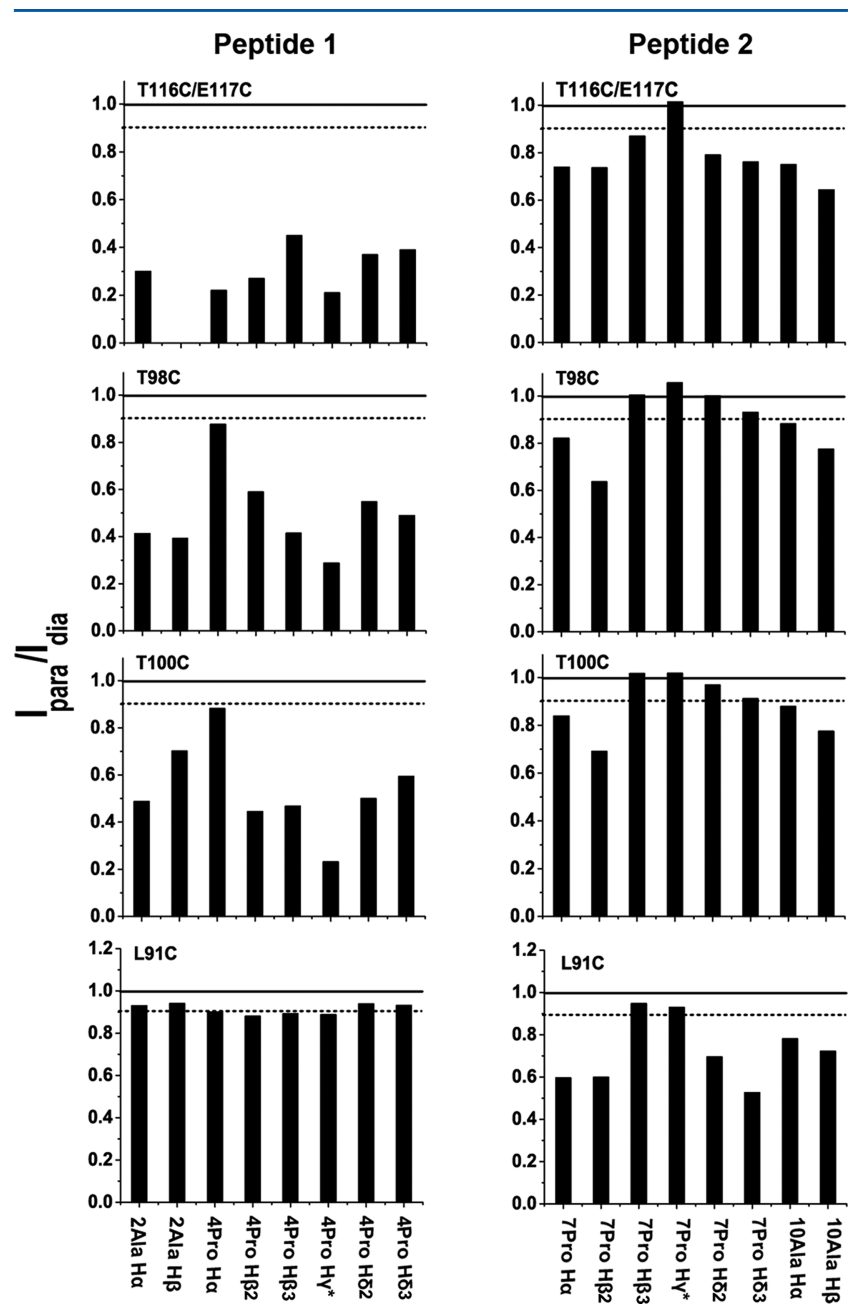

Figure 5. Paramagnetic relaxation of peptide nuclei. The ratios of $I_{\text {para }}$ and $I_{\text {dia }}$ of the ${ }^{13} \mathrm{C}$ side chain protons of peptide 1 (RALPSIPKLA, left) and peptide 2 (RALPSIPKLA, right) are plotted. Nuclei with intensity ratios of $<0.9(\cdots)$ were considered to experience a significant PRE. The solid line indicates a ratio of 1.0 .
$100 \%$ bound state using the $K_{\mathrm{d}}$ values and converted into distances.

Fraction of the Peptide in the $\mathbf{C}-\mathbf{N}$ Orientation. From the experimentally calculated positions of the $\mathrm{Gd}$ ion in CLaNP-5 and the oxygen atoms of MTSL at various sites on the $\mathrm{SH} 3$ domain, the distances to peptide nuclei were calculated for $\mathrm{N}-\mathrm{C}$ as well as $\mathrm{C}-\mathrm{N}$ orientations. For the $\mathrm{N}-$ $C$ peptide, PDB entry $1 R L Q^{17}$ was used, with the peptide sequence adjusted to that of the FAK peptide. Because only Pro and Ala residues were used to obtain distances, the nature of the remaining side chains is expected to have only a weak influence. For the $\mathrm{C}-\mathrm{N}$ orientation, the peptide was rotated from the $\mathrm{N}-\mathrm{C}$ to the $\mathrm{C}-\mathrm{N}$ terminal orientation, ensuring that both prolines still lie in the binding pocket of the $\mathrm{SH} 3$ domain (Figure 2). This rotated peptide thus mimics class 2 peptides, which bind in the $\mathrm{C}-\mathrm{N}$ orientation. The experimental distances were compared with weighed averages of the distances for combinations of the $\mathrm{N}-\mathrm{C}$ and $\mathrm{C}-\mathrm{N}$ orientations. For the range of fractions of the $\mathrm{C}-\mathrm{N}$ orientation from 0 to 1 , the fit to the experimental distances was calculated and expressed as a quality factor $Q$ (eq 5). The results for the different spin-label mutants are shown in Figure 6. The data for mutant T116C/E117C clearly show that the fit to the data improves by admixture of the $\mathrm{C}-\mathrm{N}$ orientation. This is caused by the PREs observed for the C-terminally labeled peptide. The lowest value of $Q$ was found for a combination of $80 \% \mathrm{~N}-\mathrm{C}$ orientation and $20 \% \mathrm{C}-$ $\mathrm{N}$ orientation. These results are similar for mutants T98C and T100C. For mutant L91C, small but significant PREs were observed for peptide 2 but insignificant effects for peptide 1 . The small effects cause considerable uncertainty in the distances and render the $Q$ dependence on the fraction of $\mathrm{C}-\mathrm{N}$ rather flat, but the data do not disagree with a contribution to the PREs from the $\mathrm{C}-\mathrm{N}$ orientation of $\sim 20 \%$.

The peptide derived from the FAK binding motif of the Src $\mathrm{SH} 3$ domain belongs to the class 1 sequence $(\mathrm{N}-\mathrm{C}$ orientation). PREs derived from the paramagnetic centers on mutants T116C/E117C, T98C, and T100C suggest that the peptide binds for $80 \%$ of the time in the $\mathrm{N}-\mathrm{C}$ orientation and $20 \%$ in the $\mathrm{C}-\mathrm{N}$ orientation. Although the data suggest that the $\mathrm{N}-\mathrm{C}$ conformation is not populated $100 \%$ of the time, and the $\mathrm{C}-\mathrm{N}$ conformation contributes significantly, some caution in the interpretation of data is necessary. The model for the C$\mathrm{N}$ orientation is crude, because it is not known how the FAK peptide binds exactly to the Src $\mathrm{SH} 3$ domain in that orientation. It is likely, though, that the nuclei that were labeled, in particular the Pro residues, are modeled in approximately the correct position, because the location of the Pro residues in the $\mathrm{C}-\mathrm{N}$ orientation mirrors that in the $\mathrm{N}-$ $\mathrm{C}$ orientation.

The binding maps are similar, but the affinity for the peptide of the variants with probes was weaker than for the wt $\mathrm{SH} 3$ domain. Also, two forms were observed for T98C and T100C, indicating that the $\mathrm{SH} 3$ domain assumes two conformations that differ slightly and are in slow exchange. Apparently, attachment of the probe to the small protein domain $\mathrm{SH} 3$ can easily affect its structure, and thus its interaction with the peptide. Therefore, the possibility that the introduction of the paramagnetic center influences the fraction of the peptide that binds in the $\mathrm{C}-\mathrm{N}$ orientation cannot be excluded. However, we find consistently a fraction of $20-30 \%$ of the $\mathrm{C}-\mathrm{N}$ conformation for all the probes at different positions, strengthening the conclusion that the peptide binds in two orientations. It is noted that in strict terms, the reported $K_{\mathrm{d}}$ 

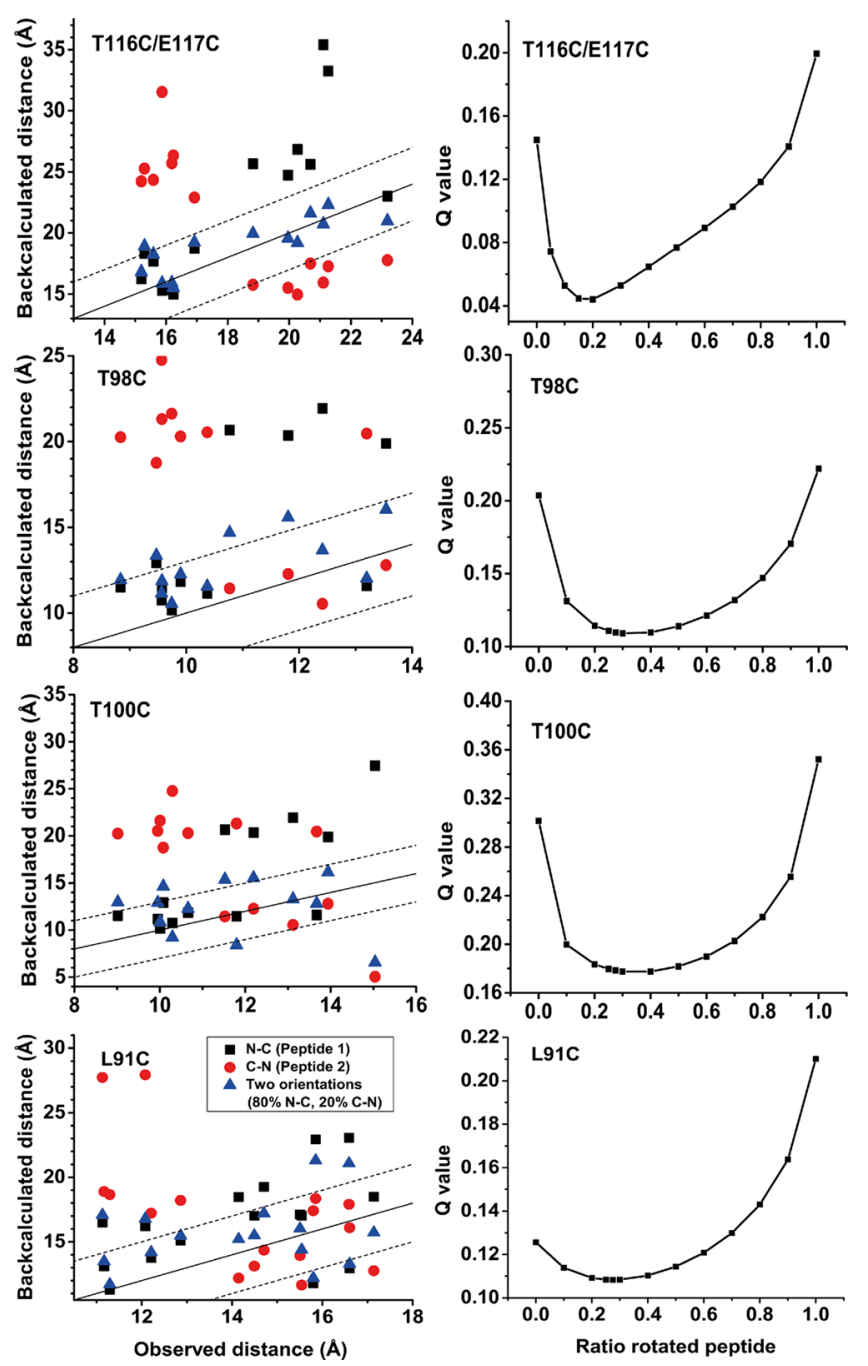

Figure 6. Determination of the fraction of the $\mathrm{C}-\mathrm{N}$ orientation of FAK peptide binding to the $\mathrm{SH} 3$ domain. The graphs on the left represent the correlation between experimental distances derived from PREs and calculated distances from the structure models of the peptide bound to the $\mathrm{SH} 3$ domain in the $\mathrm{C}-\mathrm{N}$ and $\mathrm{N}-\mathrm{C}$ orientations. The solid and dashed black lines represent the perfect correlation and the $3 \AA$ error margins, respectively. The graphs on the right show the quality of the fit to the experimental distances expressed as the $Q$ value (eq 5) as a function of the fraction of the $\mathrm{C}-\mathrm{N}$ orientation.

values are apparent $K_{\mathrm{d}}$ values, because the peptide binds in two orientations. However, the binding is in fast exchange on the NMR time scale, so the $K_{d}$ is the weighted average affinity for both orientations.

It remains to be established whether both binding modes are functionally relevant. The FAK SH3 binding site is separated from the SH2 binding site (Tyr397) by a linker of 23 amino acids, which is likely to be flexible. Earlier work from our group showed that this linker can be severely reduced in length while maintaining combined binding to the $\mathrm{SH} 3-\mathrm{SH} 2$ construct of Src. ${ }^{27}$ Thus, it seems not impossible that the SH3 binding sequence has sufficient freedom to bind in both the $\mathrm{C}-\mathrm{N}$ and $\mathrm{N}-\mathrm{C}$ orientations without compromising the binding of the $\mathrm{SH} 2$ domain to FAK.

In previous work, the peptide was labeled with a paramagnetic center by introducing a TOAC residue into the peptide. ${ }^{26}$ These studies showed that the peptide bound in a well-defined orientation despite the moderate affinity. This is in contrast with some low-affinity protein complexes in which the partners are in a dynamic encounter state for a significant fraction of the time. This conclusion was based on the welldefined CSP map and the localized paramagnetic effects caused by the TOAC radical on the $\mathrm{SH} 3$ domain. The findings in the present study are not in contrast with that conclusion. Our data suggest that the peptide binds in two well-defined orientations, with a major state and a minor state. Such a situation causes localized CSP of a large size as well as PREs averaged $\left(r^{-6}\right)$ over the two orientations. In encounter complexes, the CSP values are small because of the averaging and perhaps a lack of desolvation and PREs are usually observed over a wide area of the surface, because of the many different orientations occurring in that state.

Binding of the peptide to the $\mathrm{SH} 3$ domain in two orientations implies that the classification into $\mathrm{N}-\mathrm{C}$ and $\mathrm{C}-$ $\mathrm{N}$ orientations is a gradual rather than absolute one. Although $\mathrm{SH} 3$ domains share general features such as binding to PxxP motives, they vary in interaction specificity and preference for a specific class of peptides. Thus, our finding for the Src SH3 domain will need to be tested on other $\mathrm{SH} 3$ domains to be generalized. Crystal structures are expected to consist of one of the two forms, but it would be worth re-evaluating NMR spectra to see whether minor NOEs between the $\mathrm{SH} 3$ domain and the peptide in the minor orientation can be detected.

\section{ASSOCIATED CONTENT}

\section{Supporting Information}

The Supporting Information is available free of charge on the ACS Publications website at DOI: 10.1021/acs.biochem.5b00998.

Tables with distances between the paramagnetic centers and the $\mathrm{C} \alpha$ atoms of the respective cysteines and peptide NMR assignments and figures showing the CSP titration curves, the average chemical shift perturbations for peptide binding on the $\mathrm{SH} 3$ domain with the paramagnetic tags, $I_{\text {para }} / I_{\text {dia }}$ ratios, the positions of the paramagnetic centers relative to the $\mathrm{SH} 3$ domain, the HSQC spectrum of peptide 2, and an example of the XPLOR-NIH script of docking a SL pseudoatom (PDF)

\section{AUTHOR INFORMATION}

\section{Corresponding Author}

*E-mail: m.ubbink@chem.leidenuniv.nl. Phone: +31 71527 4628.

\section{Funding}

Financial support was provided by The Netherlands Organisation for Scientific Research (NWO), Grants 700.58.405 (P.H.J.K.) and 700.58.441 (M.U.).

\section{Notes}

The authors declare no competing financial interest.

\section{ACKNOWLEDGMENTS}

Drs. Martina Huber and Martin van Son for performing EPR measurements.

\section{ABBREVIATIONS}

CLaNP, caged lanthanoid NMR probe; CSP, chemical shift perturbation; DTT, dithiothreitol; EDTA, ethylenediaminetetraacetic acid; EPR, electron paramagnetic resonance; Fmoc, 9H-fluorenylmethyloxycarbonyl; HEPES, 4-(2-hydroxyethyl)-1- 
piperazineethanesulfonic acid; HSQC, heteronuclear singlequantum coherence; INEPT, insensitive nuclei enhanced by polarization transfer; $K_{\mathrm{d}}$, dissociation constant; LB, Lysogenic Broth; MTS, (1-acetyl-2,2,5,5-tetramethyl-3-pyrroline-3-methyl)-methanethiosulfonate; MTSL, (1-oxyl-2,2,5,5-tetramethylpyrroline-3-yl)methyl)-methanethiosulfonate; NMR, nuclear magnetic resonance; NOE, nuclear Overhauser effect; $\mathrm{SH}$, Src homology; TOAC, 2,2,6,6-tetramethylpiperidine-1-oxyl-4amino-4-carboxylic acid; wt, wild type; $\mathrm{KP}_{\mathrm{i}}$, potassium phosphate; Tris-HCl, trisaminomethane hydrochloride; PPII, polyproline type II helix structure.

\section{REFERENCES}

(1) Sen, B., and Johnson, F. M. (2011) Regulation of SRC family kinases in human cancers. J. Signal Transduction 2011, 865819.

(2) Martin-Perez, J., Garcia-Martinez, J. M., Sanchez-Bailon, M. P., Mayoral-Varo, V., and Calcabrini, A. (2015) Role of SRC family kinases in prolactin signaling. Adv. Exp. Med. Biol. 846, 163-188.

(3) Pawson, T., and Nash, P. (2003) Assembly of cell regulatory systems through protein interaction domains. Science 300, 445-452.

(4) Pawson, T. (2004) Specificity in signal transduction: from phosphotyrosine-SH2 domain interactions to complex cellular systems. Cell 116, 191-203.

(5) Li, S. S. C. (2005) Specificity and versatility of SH3 and other proline-recognition domains: structural basis and implications for cellular signal transduction. Biochem. J. 390, 641-653.

(6) Pawson, T., Gish, G. D., and Nash, P. (2001) SH2 domains, interaction modules and cellular wiring. Trends Cell Biol. 11, 504-511.

(7) Waksman, G., Kumaran, S., and Lubman, O. (2004) SH2 domains: role, structure and implications for molecular medicine. Expert Rev. Mol. Med. 6, 1-18.

(8) Saksela, K., and Permi, P. (2012) SH3 domain ligand binding: What's the consensus and where's the specificity? FEBS Lett. 586, 2609-2614.

(9) Siligardi, G., Ruzza, P., Hussain, R., Cesaro, L., Brunati, A. M., Pinna, L. A., and Donella-Deana, A. (2012) The SH3 domain of HS1 protein recognizes lysine-rich polyproline motifs. Amino Acids 42, 1361-1370.

(10) Polverini, E., Rangaraj, G., Libich, D. S., Boggs, J. M., and Harauz, G. (2008) Binding of the proline-rich segment of myelin basic protein to $\mathrm{SH} 3$ domains: spectroscopic, microarray, and modeling studies of ligand conformation and effects of posttranslational modifications. Biochemistry 47, 267-282.

(11) Aitio, O., Hellman, M., Kazlauskas, A., Vingadassalom, D. F., Leong, J. M., Saksela, K., and Permi, P. (2010) Recognition of tandem PxxP motifs as a unique Src homology 3-binding mode triggers pathogen-driven actin assembly. Proc. Natl. Acad. Sci. U. S. A. 107, 21743-21748.

(12) Aitio, O., Hellman, M., Kesti, T., Kleino, I., Samuilova, O., Pääkkönen, K., Tossavainen, H., Saksela, K., and Permi, P. (2008) Structural basis of PxxDY motif recognition in SH3 binding. J. Mol. Biol. 382, 167-178.

(13) Ball, L. J., Kuhne, R., Schneider-Mergener, J., and Oschkinat, H. (2005) Recognition of proline-rich motifs by protein-proteininteraction domains. Angew. Chem., Int. Ed. 44, 2852-2869.

(14) Hiipakka, M., and Saksela, K. (2007) Versatile retargeting of SH3 domain binding by modification of non-conserved loop residues. FEBS Lett. 581, 1735-1741.

(15) Kim, J., Lee, C. D., Rath, A., and Davidson, A. R. (2008) Recognition of non-canonical peptides by the yeast Fuslp SH3 domain: Elucidation of a common mechanism for diverse $\mathrm{SH} 3$ domain specificities. J. Mol. Biol. 377, 889-901.

(16) Mayer, B. J. (2001) SH3 domains: complexity in moderation. J. Cell Sci. 114, 1253-1263.

(17) Feng, S., Chen, J. K., Yu, H., Simon, J. A., and Schreiber, S. L. (1994) Two binding orientations for peptides to the Src SH3 domain: development of a general model for SH3-ligand interactions. Science $266,1241-1247$.
(18) Lim, W. A., Richards, F. M., and Fox, R. O. (1994) Structural determinants of peptide-binding orientation and of sequence specificity in SH3 domains. Nature 372, 375-379.

(19) Deng, L., Velikovsky, C. A., Swaminathan, C. P., Cho, S. W., and Mariuzza, R. A. (2005) Structural basis for recognition of the T cell adaptor protein SLP-76 by the SH3 domain of phospholipase C gamma 1. J. Mol. Biol. 352, 1-10.

(20) Bacarizo, J., and Camara-Artigas, A. (2013) Atomic resolution structures of the c-Src SH3 domain in complex with two high-affinity peptides from classes I and II. Acta Crystallogr., Sect. D: Biol. Crystallogr. 69, 756-766.

(21) Batra-Safferling, R., Granzin, J., Mödder, S., Hoffmann, S., and Willbold, D. (2010) Structural studies of the phosphatidylinositol 3kinase (PI3K) SH3 domain in complex with a peptide ligand: role of the anchor residue in ligand binding. Biol. Chem. 391, 33-42.

(22) Weng, Z., Thomas, S. M., Rickles, R. J., Taylor, J. A., Brauer, A. W., Seidel-Dugan, C., Michael, W. M., Dreyfuss, G., and Brugge, J. S. (1994) Identification of Src, Fyn, and Lyn SH3-binding proteins: implications for a function of SH3 domains. Mol. Cell. Biol. 14, 45094521.

(23) Bacarizo, J., Martinez-Rodriguez, S., and Camara-Artigas, A. (2015) Structure of the c-Src-SH3 domain in complex with a prolinerich motif of NS5A protein from the hepatitis C virus. J. Struct. Biol. $189,67-72$.

(24) Briggs, S. D., Bryant, S. S., Jove, R., Sanderson, S. D., and Smithgall, T. E. (1995) The Ras GTPase-activating protein (GAP) is an $\mathrm{SH} 3$ domain-binding protein and substrate for the Src-related tyrosine kinase, Hck. J. Biol. Chem. 270, 14718-14724.

(25) Weng, Z., Rickles, R. J., Feng, S., Richard, S., Shaw, A. S., Schreiber, S. L., and Brugge, J. S. (1995) Structure-function analysis of SH3 domains: $\mathrm{SH} 3$ binding specificity altered by single amino acid substitutions. Mol. Cell. Biol. 15, 5627-5634.

(26) Lindfors, H. E., de Koning, P. E., Drijfhout, J. W., Venezia, B., and Ubbink, M. (2008) Mobility of TOAC spin-labelled peptides binding to the Src SH3 domain studied by paramagnetic NMR. J. Biomol. NMR 41, 157-167.

(27) Lindfors, H. E., Venkata, B. S., Drijfhout, J. W., and Ubbink, M. (2011) Linker length dependent binding of a focal adhesion kinase derived peptide to the Src SH3-SH2 domains. FEBS Lett. 585, 601605.

(28) Volkov, A. N., Worrall, J. A., Holtzmann, E., and Ubbink, M. (2006) Solution structure and dynamics of the complex between cytochrome $\mathrm{c}$ and cytochrome $\mathrm{c}$ peroxidase determined by paramagnetic NMR. Proc. Natl. Acad. Sci. U. S. A. 103, 18945-18950.

(29) Clore, G. M., Tang, C., and Iwahara, J. (2007) Elucidating transient macromolecular interactions using paramagnetic relaxation enhancement. Curr. Opin. Struct. Biol. 17, 603-616.

(30) Iwahara, J., and Clore, G. M. (2006) Detecting transient intermediates in macromolecular binding by paramagnetic NMR. Nature 440, 1227-1230.

(31) Tang, C., Iwahara, J., and Clore, G. M. (2006) Visualization of transient encounter complexes in protein-protein association. Nature $444,383-386$

(32) Hiemstra, H. S., Duinkerken, G., Benckhuijsen, W. E., Amons, R., de Vries, R. R., Roep, B. O., and Drijfhout, J. W. (1997) The identification of $\mathrm{CD} 4+\mathrm{T}$ cell epitopes with dedicated synthetic peptide libraries. Proc. Natl. Acad. Sci. U. S. A. 94, 10313-10318.

(33) Keizers, P. H., Desreux, J. F., Overhand, M., and Ubbink, M. (2007) Increased paramagnetic effect of a lanthanide protein probe by two-point attachment. J. Am. Chem. Soc. 129, 9292-9293.

(34) Keizers, P. H., Saragliadis, A., Hiruma, Y., Overhand, M., and Ubbink, M. (2008) Design, synthesis, and evaluation of a lanthanide chelating protein probe: CLaNP-5 yields predictable paramagnetic effects independent of environment. J. Am. Chem. Soc. 130, 1480214812.

(35) Delaglio, F., Grzesiek, S., Vuister, G. W., Zhu, G., Pfeifer, J., and Bax, A. (1995) NMRPipe: a multidimensional spectral processing system based on UNIX pipes. J. Biomol. NMR 6, 277-293. 
(36) Vranken, W. F., Boucher, W., Stevens, T. J., Fogh, R. H., Pajon, A., Llinas, M., Ulrich, E. L., Markley, J. L., Ionides, J., and Laue, E. D. (2005) The CCPN data model for NMR spectroscopy: development of a software pipeline. Proteins: Struct., Funct., Genet. 59, 687-696.

(37) Tessari, M., Gentile, L. N., Taylor, S. J., Shalloway, D. I., Nicholson, L. K., and Vuister, G. W. (1997) Heteronuclear NMR studies of the combined Src homology domains 2 and 3 of pp60 c-Src: Effects of phosphopeptide binding. Biochemistry 36, 14561-14571.

(38) Battiste, J. L., and Wagner, G. (2000) Utilization of site-directed spin labeling and high-resolution heteronuclear nuclear magnetic resonance for global fold determination of large proteins with limited nuclear overhauser effect data. Biochemistry 39, 5355-5365.

(39) Garcia de la Torre, J., Huertas, M. L., and Carrasco, B. (2000) HYDRONMR: prediction of NMR relaxation of globular proteins from atomic-level structures and hydrodynamic calculations. J. Magn. Reson. 147, 138-146.

(40) Schwieters, C. D., Kuszewski, J. J., Tjandra, N., and Marius Clore, G. M. (2003) The Xplor-NIH NMR molecular structure determination package. J. Magn. Reson. 160, 65-73.

(41) Bashir, Q., Volkov, A. N., Ullmann, G. M., and Ubbink, M. (2010) Visualization of the encounter ensemble of the transient electron transfer complex of cytochrome $c$ and cytochrome $c$ peroxidase. J. Am. Chem. Soc. 132, 241-247. 